\title{
Extinction procedure induces pruning of dendritic spines in CA1 hippocampal field depending on strength of training in rats
}

\section{María E. Garín-Aguilar ${ }^{1}$, Sofía Díaz-Cintra ${ }^{2}$, Gina L. Quirarte $^{1}$, Azucena Aguilar-Vázquez $^{2}$, Andrea C. Medina ${ }^{1}$ and Roberto A. Prado-Alcalá ${ }^{1 *}$}

${ }^{1}$ Departamento de Neurobiología Conductual y Cognitiva, Instituto de Neurobiología, Universidad Nacional Autónoma de México, Querétaro, Qro., México

${ }^{2}$ Departamento de Neurobiología del Desarrollo y Neurofisiología, Instituto de Neurobiología, Universidad Nacional Autónoma de México, Querétaro, Qro., México

Edited by:

Antonella Gasbarri, University of

I'Aquila, Italy

Reviewed by:

Roberto Galvez, University of Illinois,

Urbana-Champaign, USA

Ignacio Gonzalez-Burgos, Instituto

Mexicano Del Seguro Social, Mexico

*Correspondence:

Roberto A. Prado-Alcalá,

Departamento de Neurobiología

Conductual y Cognitiva, Instituto de

Neurobiología, Universidad Nacional

Autónoma de México, Boulevard

Juriquilla 3001, Juriquilla, Querétaro.

Qro. 76230, México.

e-mail:prado@unam.mx
Numerous reports indicate that learning and memory of conditioned responses are accompanied by genesis of dendritic spines in the hippocampus, although there is a conspicuous lack of information regarding spine modifications after behavioral extinction. There is ample evidence that treatments that typically produce amnesia become innocuous when animals are submitted to a procedure of enhanced training. We now report that extinction of inhibitory avoidance (IA), trained with relatively low foot-shock intensities, induces pruning of dendritic spines along the length of the apical dendrites of hippocampal CA1 neurons. When animals are trained with a relatively high foot-shock there is a high resistance to extinction, and pruning in the proximal and medial segments of the apical dendrite are seen, while spine count in the distal dendrite remains normal. These results indicate that pruning is involved in behavioral extinction, while maintenance of spines is a probable mechanism that mediates the protecting effect against amnesic treatments produced by enhanced training.

Keywords: hippocampus, dendritic spines, pruning, extinction, inhibitory avoidance, post-traumatic stress disorder

\section{INTRODUCTION}

It has been reported that treatments that typically produce amnesia become innocuous when administered to animals that have been submitted to an enhanced learning experience. Thus, generalized interference with cholinergic or serotonergic central activity produces amnesia of inhibitory avoidance (IA) trained with relatively low levels of foot-shock, but memory remains intact when higher levels of stimulation are used during training (e.g., Duran-Arevalo et al., 1990; Galindo et al., 2008). Similarly, long-term memory deficits of IA are produced by hindrance of synaptic activity of the striatum, amygdala, and substantia nigra; in contrast, under this circumstance memory is spared after enhanced IA training (Giordano and Prado-Alcalá, 1986; PérezRuíz and Prado-Alcalá, 1989; Parent et al., 1992, 1995; Parent and McGaugh, 1994; Prado-Alcalá, 1995; Cobos-Zapiaín et al., 1996; Salado-Castillo et al., 2011). Recently, it was found that enhanced IA training prevented the typical amnesic effects of cycloheximide, a protein synthesis inhibitor (Díaz-Trujillo et al., 2009). In spite of this evidence, the neurobiological mechanisms of the protective effect of enhanced learning against amnesic treatments remain completely unknown.

The hippocampus is also involved in memory consolidation of IA training, as shown by the deleterious effects of interference with hippocampal activity on retention of this task (Izquierdo et al., 1992; Ambrogi-Lorenzini et al., 1996; Stubley-Weatherly et al., 1996; Martínez et al., 2002), although enhanced learning of this task also protects against amnesia produced by reversible blockade of hippocampal activity (Quiroz et al., 2003).
One structural neuronal change that has been proposed as a substrate of long-term memory is related to changes in dendritic spine density (Horner, 1993; O’Malley et al., 2000; Leuner et al., 2003). There is also a growing body of evidence that strongly suggests that acquisition of novel information induces the development of dendritic spines in the hippocampus in a variety of learning tasks (Mahajan and Desiraju, 1988; Horner, 1993; Moser et al., 1994; Rusakov et al., 1997; O’Malley et al., 2000; Leuner et al., 2003; Restivo et al., 2009), including the one-trial stepthrough IA task used in the present study (O'Malley et al., 1998). In this case, hippocampal dentate spine density was increased $6 \mathrm{~h}$ after training and returned to basal levels at $72 \mathrm{~h}$ after training.

Not only is the hippocampus involved in acquisition of conditioned responses, but also in the process of extinction, i.e., in the learned diminution of the conditioned responses following withholding of the unconditioned or reinforcing stimuli (Szapiro et al., 2003; Vianna et al., 2003; Dillon et al., 2008). However, there is a conspicuous lack of information regarding spine formation in this type of learning, and still less regarding extinction of enhanced learning.

The aim of this work was to determine if extinction of an IA response that had been acquired with low, medium, and high (enhanced training) levels of foot-shock promotes spinogenesis in CA1 pyramidal neurons of the hippocampus. If such were the case, then it might represent a possible mechanism for the protective effect of enhanced learning on memory. We now report that IA induces changes in spine density in CA1 pyramidal neurons 
of the hippocampus which are dependent on the strength of training.

\section{MATERIALS AND METHODS ANIMALS}

All experimental procedures were approved by the Animal Ethics Committee of Instituto de Neurobiología, Universidad Nacional Autónoma de México and were in compliance with the NIH Guidelines for the Care and Use of Laboratory Animals. The subjects were naive male Wistar rats $(250-350 \mathrm{~g})$, maintained in a room with a $12 \mathrm{~h} / 12 \mathrm{~h}$ light-dark cycle (lights on at 7:00 h), housed individually in acrylic cages with food and tap water ad libitum.

Since the main goal of this work was to determine if extinction after enhanced training of IA induces changes in spine density in the hippocampus as compared to regular training, it was necessary to operationally define "enhanced training." One way to establish such a definition was to test the effects of increasing foot-shock intensities upon resistance to extinction, which is a progressive decline in the magnitude of a conditioned response that is no longer reinforced. It is used as a measure of strength of learning, since resistance to extinction is stronger when the learning experience is also stronger. Therefore, in this experiment, independent groups of rats were given one of three different footshock intensities during training in order to find out whether in our experimental conditions a relatively high foot-shock intensity produces stronger resistance to extinction as compared with lower foot-shock intensities. There were 10 rats in each group. The brains of four animals of each group were used to analyze to the density of dendritic spines in the CA1 field of the hippocampus.

\section{APPARATUS}

The apparatus is an alley with two distinct compartments of the same size $(30 \times 30 \times 30 \mathrm{~cm})$, separated by a guillotine door. The safe compartment had walls and lid of red-colored acrylic with a floor of stainless steel bars $(6 \mathrm{~mm}$ in diameter, separated by $9 \mathrm{~mm}$ ); it was illuminated by a $10 \mathrm{~W}$ light bulb located in the center of its lid. The other non-illuminated compartment had front and back walls and floor made of stainless steel plates with its end walls and lid constructed of red-colored acrylic. The walls and floor were shaped as a trough, $20 \mathrm{~cm}$ wide at the top and $8 \mathrm{~cm}$ wide at the bottom. In the middle of the floor, a $1.5 \mathrm{~cm}$ slot separated the two stainless steel plates that make up the walls and floor. When in this compartment, the rats were in contact with both plates through which foot-shock was delivered. The apparatus was cleansed with $10 \%$ alcohol and rinsed with tap water before and after each rat occupied it. A square-pulse stimulator (Grass model No. S-48), in series with a constant current unit (Grass model No. CCU-1A) generated the foot-shock. Shock delivery and measurement of latencies to cross from one compartment to the other one were accomplished by use of automated equipment. The apparatus was located inside a dark, sound-proof room provided with background masking noise.

\section{HANDLING}

Before the behavioral experiments began each animal was handled by the experimenter. This consisted of gently touching and holding the rat with both hands using gloves for approximately 5 min for 3 consecutive days. All behavioral observations were carried out between 9:00 $\mathrm{h}$ and 13:00 $\mathrm{h}$.

\section{TRAINING AND EXTINCTION TESTING}

On the day of training each animal was put inside the safe compartment; 10 s later the door dividing the two compartments was opened and the latency to cross to the other compartment was measured (training latency). When the animals crossed to this compartment the door was closed and a foot-shock (a train of $50 \mathrm{~ms}$ square pulses at $10 \mathrm{~Hz}$ ) of 1.0, 2.0, or $3.0 \mathrm{~mA}$ was delivered. Five seconds later the door was reopened allowing the animal to escape to the safe compartment and the stimulator was turned off; this latency was also measured (escape latency). After $30 \mathrm{~s}$ in the safe compartment the animals were put back in their home cages. Starting $24 \mathrm{~h}$ after training, extinction of the task was measured on six consecutive days. To this end, the same procedure of training was followed except that the foot-shock was omitted; if the animal did not cross to the second compartment within $600 \mathrm{~s}$ a retention latency score of 600 was assigned and the session ended. After the last extinction session, four animals from each group were randomly selected to perform the histological analyses described below. Two control groups were added: one of them was subjected to the same training procedure, except that the foot-shock was not administered ( $0 \mathrm{~mA}$ group; $n=3$ ). In the case of this group, once they had crossed to the darker compartment, the door was re-opened after $5 \mathrm{~s}$, and if they did not return to the safe compartment within an additional $5 \mathrm{~s}$, they were gently pushed back into it. Twenty-four hours later, and for six consecutive days, latency to enter the dark compartment was also measured. The animals of the second control group $(n=3)$ were kept under identical living conditions as those of the animals used for the behavioral study, but they never left the bioterium, except for sacrificing (Bio group).

\section{RAPID GOLGI IMPREGNATION}

Right after the sixth test of extinction the selected animals that had been trained, together with those of the $0 \mathrm{~mA}$ and Bio groups, were anesthetized with xylazine/ketamine and perfused transcardially with a buffered solution of $10 \%$ formalin ( $\mathrm{pH}$ 7.4). After $24 \mathrm{~h}$ the brains were removed from the skull, and one $4 \mathrm{~mm}$ block containing the dorsal hippocampus (Bregma -2.8 to -4.2 ; Paxinos and Watson, 2005) was obtained from each animal. Each block of hippocampus was impregnated using the rapid Golgi technique, as modified by Diaz-Cintra et al. (1981). After 12 days, each block was transferred to a solution of $0.75 \%$ silver nitrate in double-distilled water for $12 \mathrm{~h}$, washed in $50 \%$ alcohol, embedded in low-viscosity nitrocellulose, and cut along the frontal plane at a thickness of $120 \mu \mathrm{m}$. Each section was collected in $70 \%$ alcohol, dehydrated, and mounted in Entellan medium. Each slide had 16 sections of dorsal hippocampus and was assigned a random number to ensure that observers were blind to the experimental conditions.

\section{MORPHOMETRIC ANALYSIS}

Dendritic spine counts were performed on five complete, wellimpregnated neurons of the CA1 dorsal hippocampus of each 
rat. This analysis was carried out with an Optiphot-2 Nikon microscope using a $100 \times$ objective (Plan-Apochromat, NA 0.8) and an optically calibrated reticule on the ocular $10 \times$ eyepiece. Photomicrographs were assembled from images obtained at different focal planes and reconstructed using Helicon Focus 5.1 software (LTD 2010).

The apical dendrites were divided into proximal, medial, and distal segments, where commissural, Schaffer collaterals, and perforant path fibers arrive, respectively (Amaral and Witter, 1989; Yeckel and Berger, 1990; Dudman et al., 2007). We counted the number of spines along a length of $25 \mu \mathrm{m}$ of three secondary branches of each segment. Thus, three counts per segment were obtained from each neuron. We chose to analyze secondary branches, and not the main dendritic shaft, because the proximal segment of the main apical dendrite is devoid of spines within the first $100 \mu \mathrm{m}$ from the soma (Megias et al., 2001; present inspection), and, obviously, no meaningful comparisons could have been made if the proximal segment of the main dendrite would have been taken into account. Dendritic spine density was calculated as the number of dendritic spines divided by the $25 \mu \mathrm{m}$ of the dendritic branch that was analyzed.

\section{STATISTICAL ANALYSES}

Because the measurement of retention was truncated at $600 \mathrm{~s}$, nonparametric statistics were used in analyzing the behavioral results. Independent Kruskal-Wallis analyses of variance were computed for acquisition and escape latencies, and for retention latencies of each of the extinction sessions. When appropriate, the Mann-Whitney $U$-test was used to make comparisons between any two groups.

Independent One-Way ANOVAs were used to analyse spine density in each of the three segments of the apical dendrite. This was done because their different innervations (proximal, medial, and distal segments receive commissural, Schaffer collaterals and perforant path fibers, respectively) indicates that these segments are not homogenous neuronal elements but, rather, independent functional compartments. When the F-ratios were significant, Duncan's Multiple Range Test was used to determine potential statistical differences of pair-wise comparisons.

\section{RESULTS \\ BEHAVIOR}

Training and escape latencies. The Kruskal-Wallis test revealed that there were no significant differences among the groups regarding training latencies $(H(3)=6.354, p=0.096)$. Median training latencies of the $0.0,1.0,2.0$, and $3.0 \mathrm{~mA}$ groups were: $13.0,24.56,18.13$, and $23.1 \mathrm{~s}$, respectively. Because the "escape" latency of the $0 \mathrm{~mA}$ group was not shock-motivated, in every rat this latency was higher than the median escape latency of the footshocked groups, as expected; for this reason only the 1.0, 2.0, and $3.0 \mathrm{~mA}$ groups were included in the Kruskal-Wallis analysis of escape latencies, which yielded non-significant differenced among them $(H(2)=0.467, p=0.792)$. Escape latencies of the latter groups were: $1.8,2.2$, and $2.1 \mathrm{~s}$, respectively.

Figure 1 depicts the retention of the IA behavior of each group during the 6 days of extinction. A very clear differential pattern of resistance to extinction was produced by the various foot-shock

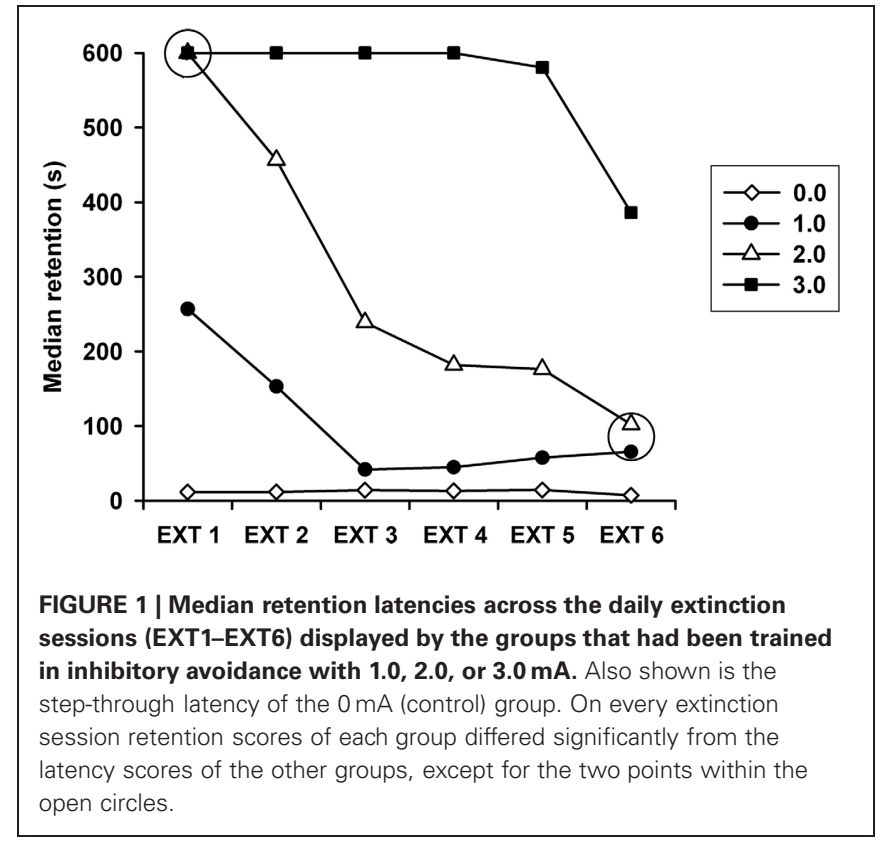

intensities used during training. The Kruskal-Wallis test revealed that there were highly significant differences among the groups on each of the six extinction sessions ( $p$ 's $<0.001$ for each session). As anticipated, the median latency scores of the $0 \mathrm{~mA}$ group were very low, always below $15 \mathrm{~s}$, and they differed from those of the other groups in each session ( $p$ 's ranging from 0.05 to $0.0001)$. At the other end, the $3.0 \mathrm{~mA}$ group displayed near perfect retention latencies on the first five extinction sessions, and a very high score on the sixth session, well above the other groups. Except for the first session, where its retention score did not differ from that of the $2.0 \mathrm{~mA}$ group, the $3.0 \mathrm{~mA}$ group had a significantly higher retention score than the other groups ( $p$ 's ranging from 0.01 to 0.0001 ) across the six sessions. The score of the $2.0 \mathrm{~mA}$ group was significantly higher than that of the $1.0 \mathrm{~mA}$ group through the first five sessions ( $p$ 's between 0.05 and 0.01 ), and in the sixth session, their performances were quite similar $(p=0.684)$.

\section{HISTOLOGY}

Figure 2 shows an example of a Golgi-stained pyramidal neuron, and magnified distal, middle and proximal segments where the number of spines was tallied along a length of $25 \mu \mathrm{m}$. The statistical analyses revealed that there were highly significant differences in spine density among the groups in the proximal $\left(F_{(4,266)}=\right.$ 9.635, $p=0.0001)$, medial $\left(F_{(4,266)}=26.978, p=0.0001\right)$, and distal $\left(F_{(4,266)}=20.245, p=0.0001\right)$ segments. The Duncan's Multiple Range Test showed that there were no significant differences in spine density between the Bio and the $0 \mathrm{~mA}$ groups in any of the segments (Figure 3). Regarding the proximal segment, spine density of the Bio and the $0 \mathrm{~mA}$ groups was significantly higher than that of the 1.0,2.0, and $3.0 \mathrm{~mA}$ groups; spine density was not significantly different among the latter three groups. In the medial segment, the Bio and the $0 \mathrm{~mA}$ groups also had a higher spine density than the 1.0, 2.0, and 3.0 mA groups; in turn, 


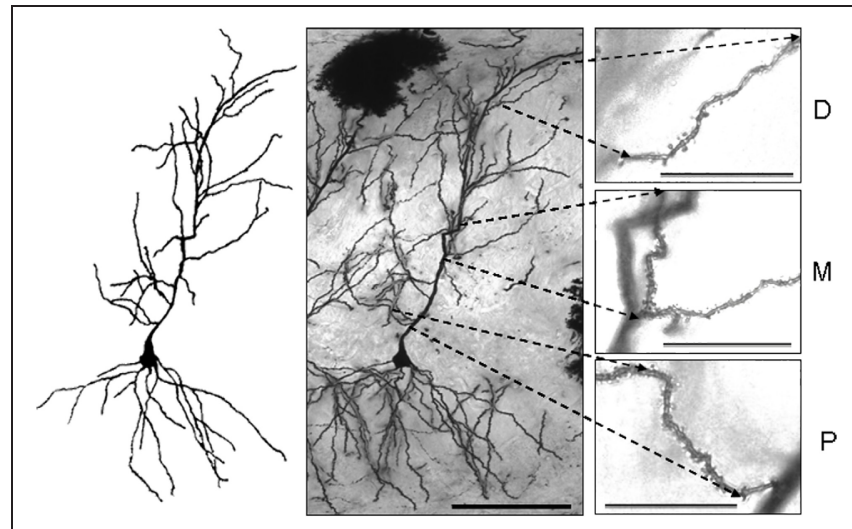

FIGURE 2 | Representative example of CA1 pyramidal cells stained with the rapid-Golgi technique (middle figure), and a camera lucida drawing of it (left figure). Insets on the right hand side show enlarged images of distal (D), medial (M), and proximal (P) segments of the apical dendrite. Dendritic spines could be easily seen in each image with examination at different focal planes. Scale bars: middle figure $(20 \times)=100 \mu \mathrm{m}$; insets $(100 x)=25 \mu \mathrm{m}$.

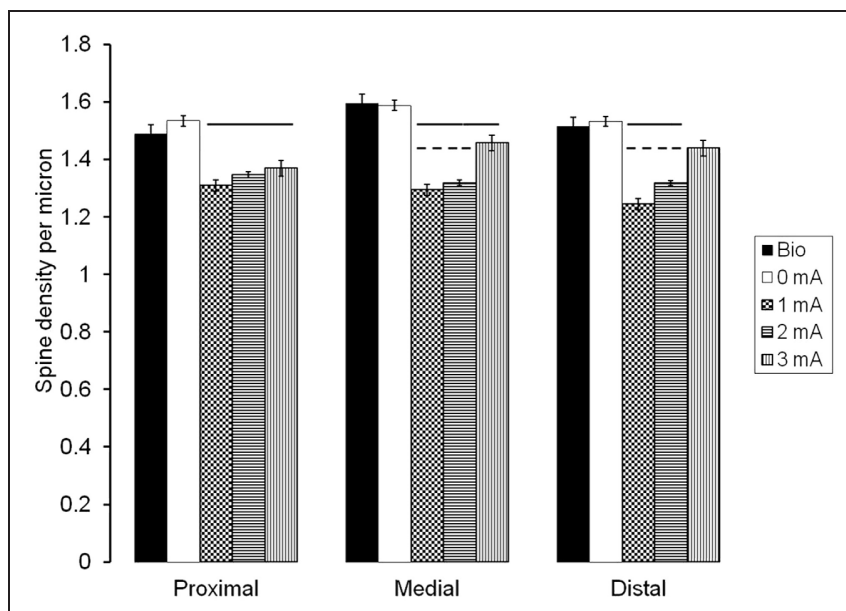

FIGURE 3 | Mean spine density values (spines per micrometer) in each of the three segments of the CA1 apical dendrite, found after six extinction sessions of animals trained in inhibitory avoidance with 0 , 1.0, 2.0, or 3.0 $\mathrm{mA}$, and of a control group that never left the bioterium, except for sacrificing (Bio). Solid lines over bars represent significant differences $(p<0.001)$ as compared to Bio and $0 \mathrm{~mA}$ groups; broken lines over bars represent significant differences $(p<0.001)$ as compared to the 3.0 mA group.

the $3.0 \mathrm{~mA}$ group showed a higher spine density than the 1.0 and $2.0 \mathrm{~mA}$ groups. Finally, in the distal segment, no significant differences among the Bio, $0 \mathrm{~mA}$, and $3.0 \mathrm{~mA}$ groups were found; each of these groups differed significantly from the 1.0 and $2.0 \mathrm{~mA}$ groups.

Percent change in spine density, relative to the Bio control group is depicted in Figure 4. It can be clearly seen the spine pruning in the three segments of the apical CA1 dendrite of all the trained groups, except that the high foot-shock group maintained normal spine density in the distal segment.

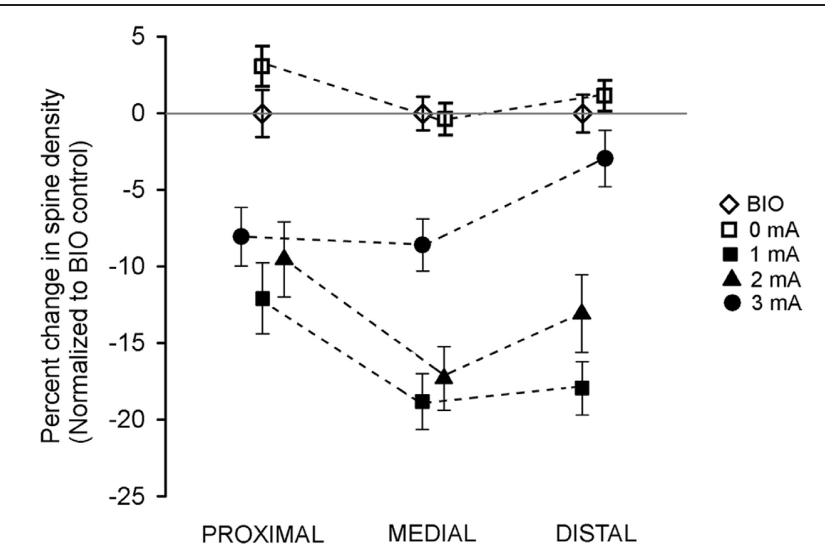

FIGURE 4 | Effects of intensity of inhibitory avoidance training on percentage changes in spine density found after six extinction sessions, normalized to the $\mathrm{BIO}$ control group, in each of the three segments of the apical dendrites of neurons of the CA1 dorsal hippocampus of the rat.

\section{DISCUSSION}

This is the first study, to our knowledge, to examine spine plasticity in the hippocampus after a procedure of extinction.

Two main results were obtained. First, as expected, the higher foot-shock intensity induced better learning, i. e., the $3.0 \mathrm{~mA}$ group showed significantly higher resistance to extinction, as it performed better than the other groups on the extinction sessions.

The second main finding was that extinction produced pruning of spines in the three segments of the apical dendrite in the groups that had been trained with the lower foot-shock intensities (1.0 and $2.0 \mathrm{~mA}$ ). Just as interesting was the observation that animals submitted to an enhanced learning experience $(3.0 \mathrm{~mA}$ group), which produced higher resistance to extinction, showed different spine densities along the length of the apical dendrite: there was pruning in the proximal segment, as was the case for the lower foot-shock groups, a significant increase in spine density in the medial segment, and a spine density that was as high as that of the control groups in the distal segment.

The reduction in spine numbers after extinction was not simply due to exposure to the experimental context nor to habituation to it; this inference can be made because such a reduction in spines was not observed in the group that was "trained" with $0 \mathrm{~mA}$ and exposed to the same context for the same number of sessions as the trained, foot-shocked groups.

The presumption that synaptic changes underlie memory storage is not new. On the first half of the twentieth century Pavlov (1927) and Konorski (1948) postulated that conditioning was a form of learning different from that engaged in extinction but that, nonetheless, these two learning processes were associated with the making of new synaptic connections. There is a good deal of experimental support for the notion that learning is associated to genesis of dendritic spines (Rusakov et al., 1997; O’Malley et al., 1998, 2000; Leuner et al., 2003; Marrone, 2007), but it is difficult to find reports dealing with spine dynamics and extinction.

Our results point to one probable mechanism of extinction and of the protective effect of enhanced learning against 
interference with long-term memory formation. It was quite clear that those groups that actually showed extinction (1.0 and $2.0 \mathrm{~mA}$ groups; Figure 1) also presented a significant degree of spine pruning along the three segments of the CA1 apical dendrites (Figure 3). In this case, the plastic change induced by extinction was in the form of a reduction of synaptic contacts in the apical dendrite, as can be implied by the reduction of spines, and suggests that extinction is linked to a decrement in excitatory inputs at the postsynaptic site. This finding goes counter to the hypotheses proposed by Pavlov (1927) and Konorski (1948), and clearly shows that the mechanisms underlying the new learned response (extinction) are quite different from that those mediating the original learning of the IA response, where spine density has been found to increase significantly (O'Malley et al., 1998).

On the other hand, the group that was trained with the highest foot-shock intensity $(3.0 \mathrm{~mA})$, showed perfect retention of the conditioned response through the first four sessions of extinction, and it was on the fifth session that this response only begun to decline. Thus, it is obvious that the behavior of this group reflected the effects of enhanced training. This heightened resistance to extinction was accompanied by a differential pattern of spine modifications through the length of the CA1 apical dendrite (Figure 4). Just as in the case of training with the lower footshock intensities, this group showed pruning in the proximal and medial segments of the apical dendrite. However, in the distal segment spine count was not different from the control groups. This interesting result may indicate that the maintenance of the conditioned response of this group, in spite of having been submitted to the process of extinction, may be due, at least in part, to the maintenance of synaptic connections mediated by these dendritic spines. The main afferent fibers of the distal segment of the apical dendrite, the perforant path, arise from the multimodal entorhinal cortex. It is tempting to speculate that this pathway conveys excitatory signals produced by the enhanced learning conditions, thus halting the natural pruning induced by the extinction of the conditioned response.

In a recent and stimulating article, Vetere et al. (2011) studied dendritic spine dynamics after long-term retention of contextual fear conditioning. A significant increase in the density and size of spines was found in the apical dendrites of the anterior cingulated and infralimbic cortices. Interestingly, after extinction of the conditioned response spine density returned to baseline but the proportion of large spines did not in the anterior cingulated cortex; the opposite outcome was seen in the infralimbic cortex. These authors concluded that fluctuations in spine density and spine shape occur in cortical regions during both the formation and the extinction of contextual fear memories. On the other hand, we found that extinction was accompanied by pruning of dendritic spines along the length of the apical dendrites

\section{REFERENCES}

Amaral, D. G., and Witter, M. P. (1989).

The three-dimensional organization of the hippocampal formation: a review of anatomical data. Neuroscience 31, 571-591.

Ambrogi-Lorenzini, C., Baldi, E., Bucherelli, C., Sacchetti, B., and
Tassoni, G. (1996). Role of dorsal hippocampus in acquisition, consolidation and retrieval of rat's passive avoidance response: a tetrodotoxin functional inactivation study. Brain Res. 730, 32-39.

Armario, A., Escorihuela, R. M., and Nadal, R. (2008). Long-term

of hippocampal CA1 cells of rats that had been trained in IA with relatively low foot-shocks, and no change in spine density in the distal dendrite when a high foot-shock was administered. These dissimilar findings show that extinction learning represents a complex phenomenon where different processes take place in different brain regions, which may be dependent upon the type of behavior that is being extinguished.

It is worth mentioning that one distinctive feature of posttraumatic stress disorder (PTSD) is the formation of a strong memory that is highly resistant to extinction (Armario et al., 2008), akin to the memory formed after the enhanced learning of IA described in the present work. Thus, this behavioral model might be useful in the study of the neurobiology of PTSD, and one is tempted to hypothesize that resistance to extinction seen in this pathology could also be mediated by the durability of dendritic spines in the apical dendrites of the hippocampal pyramidal neurons.

To conclude, training of IA with a foot-shock of relatively high intensity $(3.0 \mathrm{~mA})$ produced enhanced learning, as shown by the strong resistance to extinction, as compared to the performance of the groups that had been trained with lower foot-shock intensities. After testing under a protocol to produce extinction, there was pruning of dendritic spines along the length of the apical dendrites in neurons of the CA1 field of the hippocampus in the animals that were trained with the lower foot-shock intensities (1.0 and $2.0 \mathrm{~mA}$ ); these animals showed weak resistance to extinction. The group with the strong resistance to extinction also showed pruning of dendritic spines, but only in the proximal and medial segments of the apical dendrite; normal spine counts were found in the distal segment. Behavioral extinction, evidenced by the low retention scores, may be mediated, in part, by a plastic change in the form of a reduction of synaptic contacts in the apical dendrite, while maintenance of the conditioned response after the extinction protocol may be due, at least in part, to the maintenance of synaptic connections in the distal segment of the apical dendrite.

Further research is needed to put to the experimental test the various interpretations to the results offered in this work.

\section{ACKNOWLEDGMENTS}

We thank Ángel Méndez, Norma Serafín, Omar González, Martín García, and Ramón Martínez Olvera for their excellent technical assistance; and Dr. Dorothy Plerss for reviewing and helping us to improve the manuscript. Supported by the National Council of Science and Technology of México (Grant CONACYT 128259) and by PAPIIT-DGAPA-UNAM (Grant IN201712). This work was carried out in partial fulfillment of the requirements to obtain the Doctor's Degree (Doctorado en Ciencias Biomédicas, UNAM) by M. E. Garín-Aguilar, who was a recipient of a Graduate Scholarship from CONACYT (171434).

neuroendocrine and behavioura effects of a single exposure to stress in adult animals. Neurosci. Biobehav. Rev. 32, 1121-1135.

Cobos-Zapiaín, G. G., Salado-Castillo, R., Sánchez-Alavez, M., Quirarte, G. L., Roldán-Roldán, G., Díaz del Guante, M. A., and Prado-Alcalá,
R. A. (1996). High level of footshock during inhibitory avoidance training prevents amnesia induced by intranigral injection of GABA antagonists. Neurobiol. Learn. Mem. 65, 202-206.

Diaz-Cintra, S., Cintra, L., Kemper, T., Resnick, O., and Morgane, P. J. 
(1981). Nucleus raphe dorsalis: a morphometric Golgi study in rats of three age groups. Brain Res. 207, $1-16$.

Díaz-Trujillo, A., Contreras, J., Medina, A. C., Silveyra-Leon, G. A., Quirarte, G. L., and Prado-Alcalá, R. A. (2009). Enhanced inhibitory avoidance learning prevents the long-term memory-impairing effects of cycloheximide, a protein synthesis inhibitor. Neurobiol. Learn. Mem. 91, 310-314.

Dillon, G. M., Qu, X., Marcus, J. N., and Dodart, J. C. (2008). Excitotoxic lesions restricted to the dorsal CAl field of the hippocampus impair spatial memory and extinction learning in C57BL/6 mice. Neurobiol. Learn. Mem. 90, 426-433.

Dudman, J. T., Tsay, D., and Siegelbaum, S. A. (2007). A role for synaptic inputs at distal dendrites: instructive signals for hippocampal long-term plasticity. Neuron 56, 866-879.

Duran-Arevalo, M., Cruz-Morales, S. E., and Prado-Alcalá, R. A. (1990). Is acetylcholine involved in memory consolidation of over-reinforced learning? Brain Res. Bull. 24, 725-727.

Galindo, L. E., Garín-Aguilar, M. E., Medina, A. C., Serafín, N., Quirarte, G. L., and Prado-Alcalá, R. A. (2008). Acquisition and retention of enhanced active avoidance are unaffected by interference with serotonergic activity. Behav. Brain Res. 195, 153-158.

Giordano, M., and Prado-Alcalá, R. A. (1986). Retrograde amnesia induced by post-trial injection of atropine into the caudate-putamen Protective effect of the negative reinforcer. Pharmacol. Biochem. Behav. 24, 905-909.

Horner, C. H. (1993). Plasticity of the dendritic spine. Prog. Neurobiol. 41, 281-321.

Izquierdo, I., Da Cunha, C., Rosat, R., Jerusalinsky, D., Ferreira, M. B., and Medina, J. H. (1992). Neurotransmitter receptors involved in post-training memory processing by the amygdala, medial septum, and hippocampus of the rat. Behav. Neural Biol. 58, 16-26.

Konorski, J. (1948). Conditioned Reflexes and Neuron Organization. Cambridge, MA: Cambridge University Press.

Leuner, B., Falduto, J., and Shors, T. J. (2003). Associative memory formation increases the observation of dendritic spines in the hippocampus. J. Neurosci. 23, 659-665.

Mahajan, D. S., and Desiraju, T. (1988). Alterations of dendritic branching and spine densities of hippocampal CA3 pyramidal neurons induced by operant conditioning in the phase of brain growth spurt. Exp. Neurol. 100, 1-15.

Marrone, D. F. (2007). Ultrastructural plasticity associated with hippocampal-dependent learning: a metaanalysis. Neurobiol. Learn. Mem. 87, 361-371.

Martínez, I., Quirarte, G. L., DíazCintra, S., Quiroz, C., and Prado-Alcalá, R. A. (2002). Effects of lesions of hippocampal fields CA1 and CA3 on acquisition of inhibitory avoidance. Neuropsychobiology 46, 97-103.

Megias, M., Emri, Z., Freund, T. F., and Gulyas, A. I. (2001). Total number and distribution of inhibitory and excitatory synapses on hippocampal CA1 pyramidal cells. Neuroscience $102,527-540$

Moser, M. B., Trommald, M., and Andersen, P. (1994). An increase in dendritic spine density on hippocampal CA1 pyramidal cells following spatial learning in adult rats suggests the formation of new synapses. Proc. Natl. Acad. Sci. U.S.A. 91, 12673-12675.

O'Malley, A., O'Connell, C., Murphy, K. J., and Regan, C. M. (2000). Transient spine density increases in the mid-molecular layer of hippocampal dentate gyrus accompany consolidation of a spatial learning task in the rodent. Neuroscience 99, 229-232.

O'Malley, A., O'Connell, C., and Regan, C. M. (1998). Ultrastructural analysis reveals avoidance conditioning to induce a transient increase in hippocampal dentate spine density in the 6 hour post-training period of consolidation. Neuroscience 87, 607-613.

Parent, M. B., and McGaugh, J. L. (1994). Posttraining infusion of lidocaine into the amygdala basolateral complex impairs retention of inhibitory avoidance training. Brain Res. 661, 97-103.

Parent, M. B., Quirarte, G. L., Cahill, L., and McGaugh, J. L. (1995). Spared retention of inhibitory avoidance learning after posttraining amygdala lesions. Behav. Neurosci. 109, 803-807.
Parent, M. B., Tomaz, C., and McGaugh, J. L. (1992). Increased training in an aversively motivated task attenuates the memory-impairing effects of posttraining $\mathrm{N}$-methyl-D-aspartateinduced amygdala lesions. Behav. Neurosci. 106, 789-797.

Pavlov, I. P. (1927). Conditioned Reflexes: An Investigation of the Physiological activity of the Cerebral Cortex. London: Oxford University Press.

Paxinos, G., and Watson, C. (2005). The Rat Brain in Stereotaxic Coordinates. San Diego, CA: Academic Press.

Pérez-Ruíz, C., and Prado-Alcalá, R. A. (1989). Retrograde amnesia induced by lidocaine injection into the striatum: protective effect of the negative reinforcer. Brain Res. Bull. 22, 599-603.

Prado-Alcalá, R. A. (1995). "Serial and parallel processing during memory consolidation," in Plasticity in The Central Nervous System: Learning and Memory, eds J. L. McGaugh, F. Bermúdez-Rattoni, and R. A. Prado-Alcalá (New Jersey: Erlbaum), 57-65.

Quiroz, C., Martínez, I., Quirarte, G. L., Morales, T., Díaz-Cintra, S. and Prado-Alcalá, R. A. (2003). Enhanced inhibitory avoidance learning prevents the memoryimpairing effects of post-training hippocampal inactivation. Exp. Brain Res. 153, 400-402.

Restivo, L., Vetere, G., Bontempi, B., and Ammassari-Teule, M. (2009). The formation of recent and remote memory is associated with time-dependent formation of dendritic spines in the hippocampus and anterior cingulate cortex. J. Neurosci. 29, 8206-8214.

Rusakov, D. A., Davies, H. A., Harrison, E., Diana, G., Richter-Levin, G., Bliss, T. V., and Stewart, M. G. (1997). Ultrastructural synaptic correlates of spatial learning in rat hippocampus. Neuroscience 80 , 69-77.

Salado-Castillo, R., Sánchez-Alavéz M., Quirarte, G. L., Martínez García, M. I., and Prado-Alcalá, R. A. (2011). Enhanced training protects memory against amnesia produced by concurrent inactivation of amygdala and striatum, amygdala and substantia nigra, or striatum and substantia nigra. Front. Behav. Neurosci. 5:83. doi: 10.3389/fnbeh.2011. 00083.
Stubley-Weatherly, L., Harding, J. W., and Wright, J. W. (1996). Effects of discrete kainic acidinduced hippocampal lesions on spatial and contextual learning and memory in rats. Brain Res. 716, 29-38.

Szapiro, G., Vianna, M. R., McGaugh, J. L., Medina, J. H., and Izquierdo, I. (2003). The role of NMDA glutamate receptors, PKA, MAPK, and CAMKII in the hippocampus in extinction of conditioned fear. Hippocampus 13, 53-58.

Vetere, G., Restivo, L., Novembre, G., Aceti, M., Lumaca, M., and Ammassari-Teule, M. (2011). Extinction partially reverts structural changes associated with remote fear memory. Learn. Mem. $18,554-557$.

Vianna, M. R., Igaz, L. M., Coitinho, A. S., Medina, J. H., and Izquierdo, I. (2003). Memory extinction requires gene expression in rat hippocampus. Neurobiol. Learn. Mem. 79, 199-203.

Yeckel, M. F., and Berger, T. W. (1990). Feedforward excitation of the hippocampus by afferents from the entorhinal cortex: redefinition of the role of the trisynaptic pathway. Proc. Natl. Acad. Sci. U.S.A. 87, 5832-5836

Conflict of Interest Statement: The authors declare that the research was conducted in the absence of any commercial or financial relationships that could be construed as a potential conflict of interest.

Received: 30 January 2012; paper pending published: 14 February 2012; accepted: 01 March 2012; published online: 16 March 2012.

Citation: Garin-Aguilar ME, DíazCintra S, Quirarte GL, Aguilar-Vázquez $A$, Medina AC and Prado-Alcalá RA (2012) Extinction procedure induces pruning of dendritic spines in CA1 hippocampal field depending on strength of training in rats. Front. Behav. Neurosci. 6:12. doi: 10.3389/fnbeh.2012.00012 Copyright (c) 2012 Garín-Aguilar, Díaz-Cintra, Quirarte, Aguilar-Vázquez, Medina and Prado-Alcalá. This is an open-access article distributed under the terms of the Creative Commons Attribution Non Commercial License, which permits non-commercial use, distribution, and reproduction in other forums, provided the original authors and source are credited. 